\title{
KILAT
}

Vol. 9, No. 1, April 2020, P-ISSN 2089-1245, E-ISSN 2655-4925

DOI: https://doi.org/10.33322/kilat.v9i1.752

\section{Pembuatan Prototype Smart Power Strip Berbasis Mobile}

\author{
Andi Dahroni ${ }^{1}$ Muhammad Fadli PrathamaI $^{2}$ : Eka Putra ${ }^{3}$ \\ 1, 2, 3 Institut Teknologi PLN \\ ${ }^{1}$ andidahroni@itpln.ac.id
}

\begin{abstract}
Controlling electrical equipment within a certain time frame is one thing that is quite important. By controlling existing equipment in the house such as air conditioning, TV, fans, etc. It is often found that some electrical tools that survive are not used, in addition to waste also shortens the life of the electrical appliances. Therefore we need control and supervision of electrical devices using intelligent power strips. IoT or commonly known as the internet from things that are concepts that are intended to get the concept of the benefits of internet connectivity that is connected continuously. This concept can be used for monitoring and controlling electrical equipment that connects smart electrical terminals or power strips. By using an electrical terminal device that is paired with a system and module that can be controlled using a smartphone. Android is one of the many smartphone OSes that can bridge or facilitate all human work, one of which is in terms of control, which functions from this android as a remote control media that can be accessed by electronic devices in the home and certainly has connected first with the IoT module. This study discusses making smart sockets or smart power strips that can be rotated using a smartphone so that any electrical equipment can be used on users who do not use home.
\end{abstract}

Keywords: Smart Power Strip, IoT, Controlling

\begin{abstract}
ABSTRAK
Controlling peralatan listrik dalam rentang waktu tertentu merupakan salah satu hal yang cukup penting. Dengan pengontrolan alat-alat yang berada di dalam rumah seperti AC, TV, kipas angin, dll. Sering dijumpai beberapa alat listrik yang masih tetap hidup walaupun tidak dipakai, selain suatu pemborosan juga memperpendek umur pakai alat-alat listrik. Oleh karena itu diperlukan pengontrolan dan pengawasan terhadap pengoperasian alat-alat listrik dengan menggunakan smart power strip. IoT atau biasa dikenal dengan internet of things merupakan sebuah konsep yang bertujuan untuk memperluas konsep manfaat dari konektifitas internet yang tersambung secara terus menerus. Konsep ini bisa digunakan untuk pengawasan dan pengontrolan peralatan listrik yang tersambung terminal listrik pintar atau smart power strip. Dengan menggunakan alat terminal listrik yang dipasangkan sistem dan modul agar bisa di kontrol menggunakan smartphone. Android adalah salah satu dari sekian banyak OS smartphone yang dapat menjembatani ataupun mempermudah segala pekerjaan manusia, salah satunya dalam hal controlling, yang mana fungsi dari android ini adalah sebagai media control jarak jauh yang dapat memantau aktifitas dari alat elektronik yang berada didalam rumah dan pastinya telah terhubung terlebih dahulu dengan modul IoT. Penelitian ini membahas pembuatan stop kontak pintar atau smart power strip yang dapat di kendalikan menggunakan smartphone agar setiap peralatan listrik dapat atur meskipun pengguna tidak berada di rumah.
\end{abstract}

Kata kunci: Smart Power Strip, IoT, pengontrolan 


\section{PENDAHULUAN}

Energi listrik merupakan salah satu kebutuhan manusia yang sangat penting dan tidak dapat dilepaskan dari kebutuhan sehari-hari. Hampir semua pekerjaan manusia membutuhkan energi listrik. Kekurangan energi listrik dapat mengganggu aktivitas manusia. Maka dari itu ketersediaan energi listrik harus dipertahankan. Di Indonesia, jika dilihat dari pertumbuhan penduduk maka kebutuhan akan energi listrik terus meningkat. Menurut data penjualan tenaga listrik PLN yang dikeluarkan oleh Menteri ESDM [1], menunjukan bahwa jumlah total pelanggan tahun 2016 mencapai 64.282 .493 pelanggan.

Dibandingkan dengan tahun 2015 angka ini naik sebesar 3.114.513 pelanggan atau 4.84\%. Dari jumlah pelanggan seluruhnya, kelompok rumah tangga merupakan jumlah terbesar yaitu 59.243.672 pelanggan atau 92,16\%. Dari data tersebut, sektor rumah tangga mempunyai peran besar dalam penggunaan pasokan energi listrik di Indonesia. Namun kesadaran dari pelanggan sektor rumah tangga akan penghematan energi listrik masih sangat kurang. Menurut Direktur Jenderal Energi Baru Terbarukan dan Konservasi Energi (EBTKE) gaya hidup tidak hemat disebabkan berbagai faktor, antara lain ketidakpedulian dan belum terganggunya masyarakat dengan besaran kewajiban yang harus dibayarkan untuk mendapatkan energi listrik [2]. Menurut General Manager PLN Wilayah Babel Zulfarida Paluzi, kesadaran masyarakat akan hemat energi listrik perlu ditingkatkan melalui edukasi dan sosialisasi untuk menambah kepedulian dan pengetahuan masyarakat terhadap pentingnya penghematan listrik [3]. Banyaknya aktivitas masyarakat setiap hari yang menyebabkan sering lalai ataupun tidak begitu memperhatikan bagaimana pemakaian dari listrik, sebagai contohnya tidak sengaja tidak mematikan lampu, televisi, dan AC saat pergi keluar [4]. Maka dari itu disini peneliti mencoba membuat sebuah alat sekaligus software berbasis mobile untuk mengendalikan peralatan elektronik yang tadinya digunakan tapi lupa dimatikan dengan nama "smart power strip" atau biasa disebut dengan terminal listrik pintar. 
KILAT

Vol. 9, No. 1, April 2020, P-ISSN 2089-1245, E-ISSN 2655-4925

DOI: https://doi.org/10.33322/kilat.v9i1.752

\section{METODE/PERANCANGAN PENELITIAN}

\subsection{Proses Penelitian}

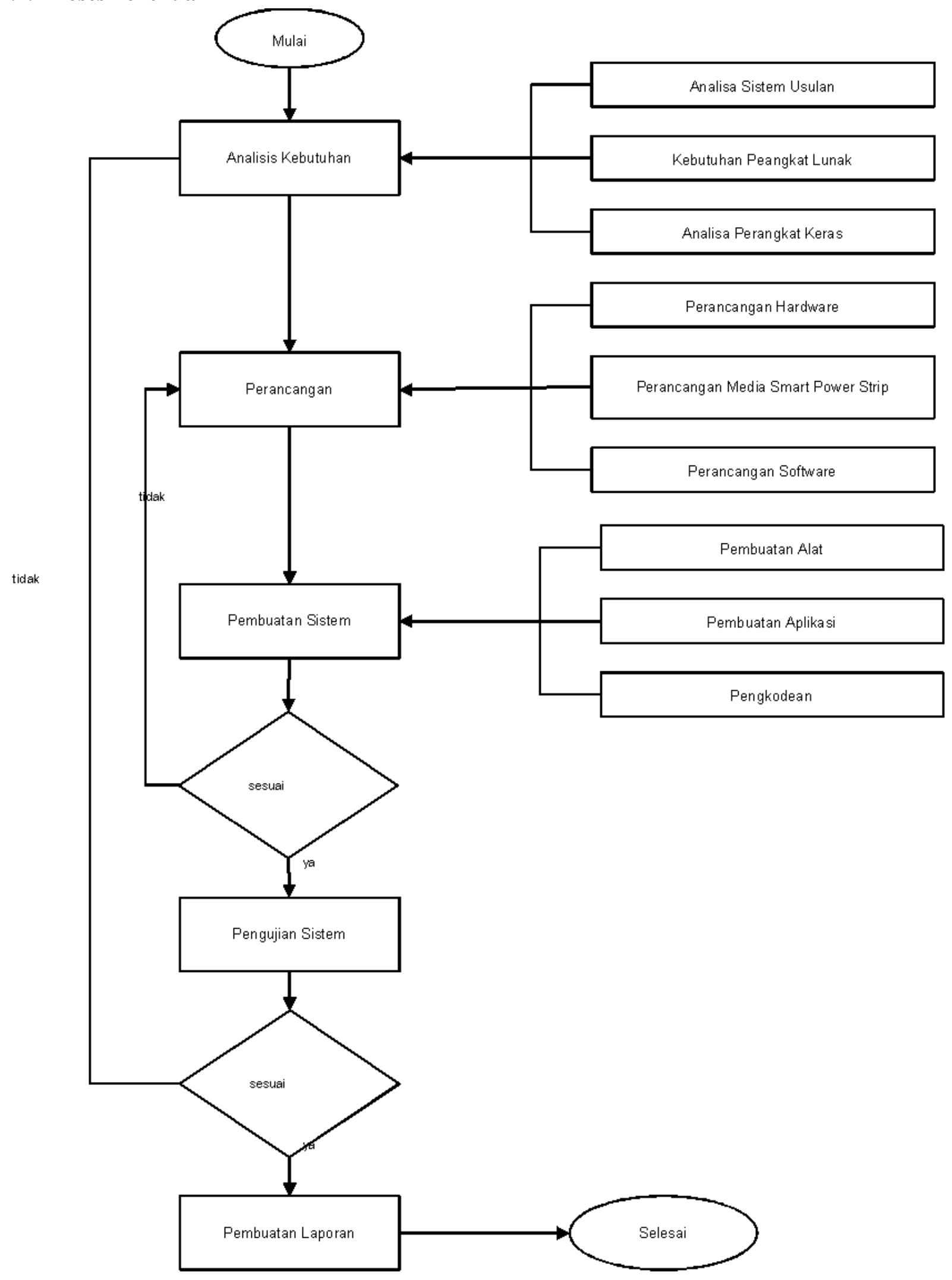

Gambar 1. Proses penelitian 
Proses Penelitian ini di bagi menjadi beberapa tahapan yaitu:

\section{Analisis kebutuhan}

Tahapan awal dari pembangunan sistem multimedia pembelajaran ini yaitu melakukan analisa terhadap kebutuhan pengguna dan kebutuhan sistem yang akan dirancang untuk mengatasi masalah yang ada.

\section{Perancangan}

Pada tahapan ini dilakukan perancangan alat, media stop kontak pintar, dan perancangan aplikasi.

Alat yang digunakan:

1. Terminal Socket outlet

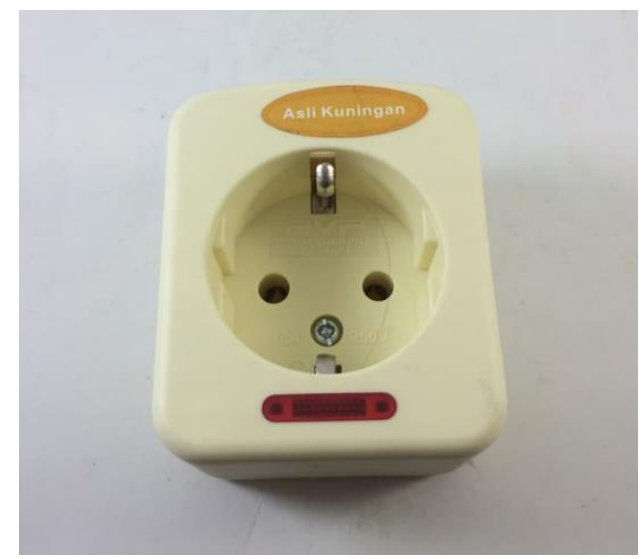

Gambar 2. Terminal socker outlet

2. Relay 4 Module

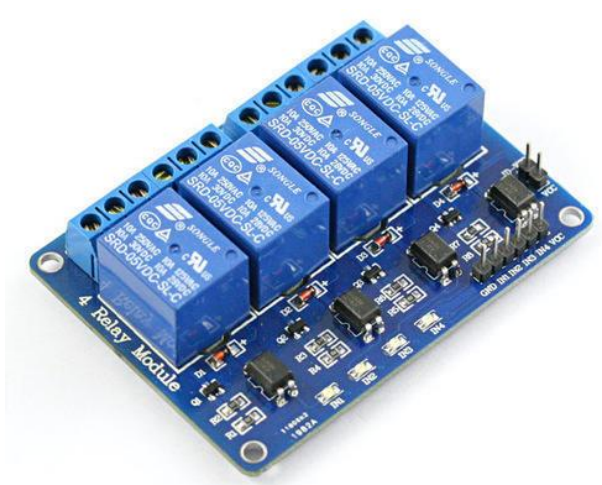

Gambar 3. Relay 4 Modul

3. Node MCU

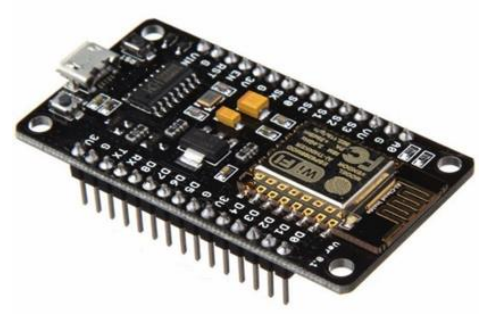

Gambar 4. Node MCU 


\section{KILAT}

Vol. 9, No. 1, April 2020, P-ISSN 2089-1245, E-ISSN 2655-4925

DOI: https://doi.org/10.33322/kilat.v9i1.752

Sebagai procecornya, mengatur jaringan wifi, dan mengontrol relay

4. Kabel Jumper

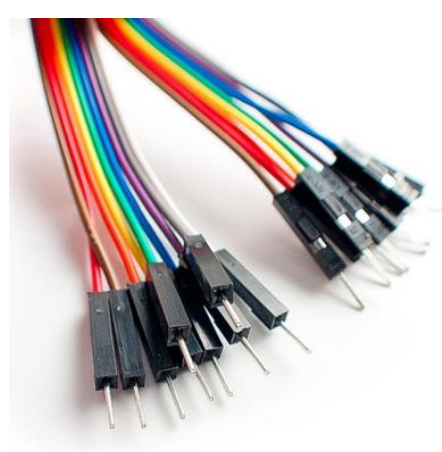

Gambar 5. Kabel Jumper

\section{Pembuatan sistem.}

Pada tahapan ini dilakukan pembuatan sistem meliputi pembuatan alat, aplikasi, dan melakukan pengkodingan. Dimana hasil yang di harapkan adalah dapat saling berkoneksinya antara software dan hardware sebagaimana tercapainya tujuan dari penelitian.

Pengkodean dilakukan pada Aplikasi Arduino Sketch.

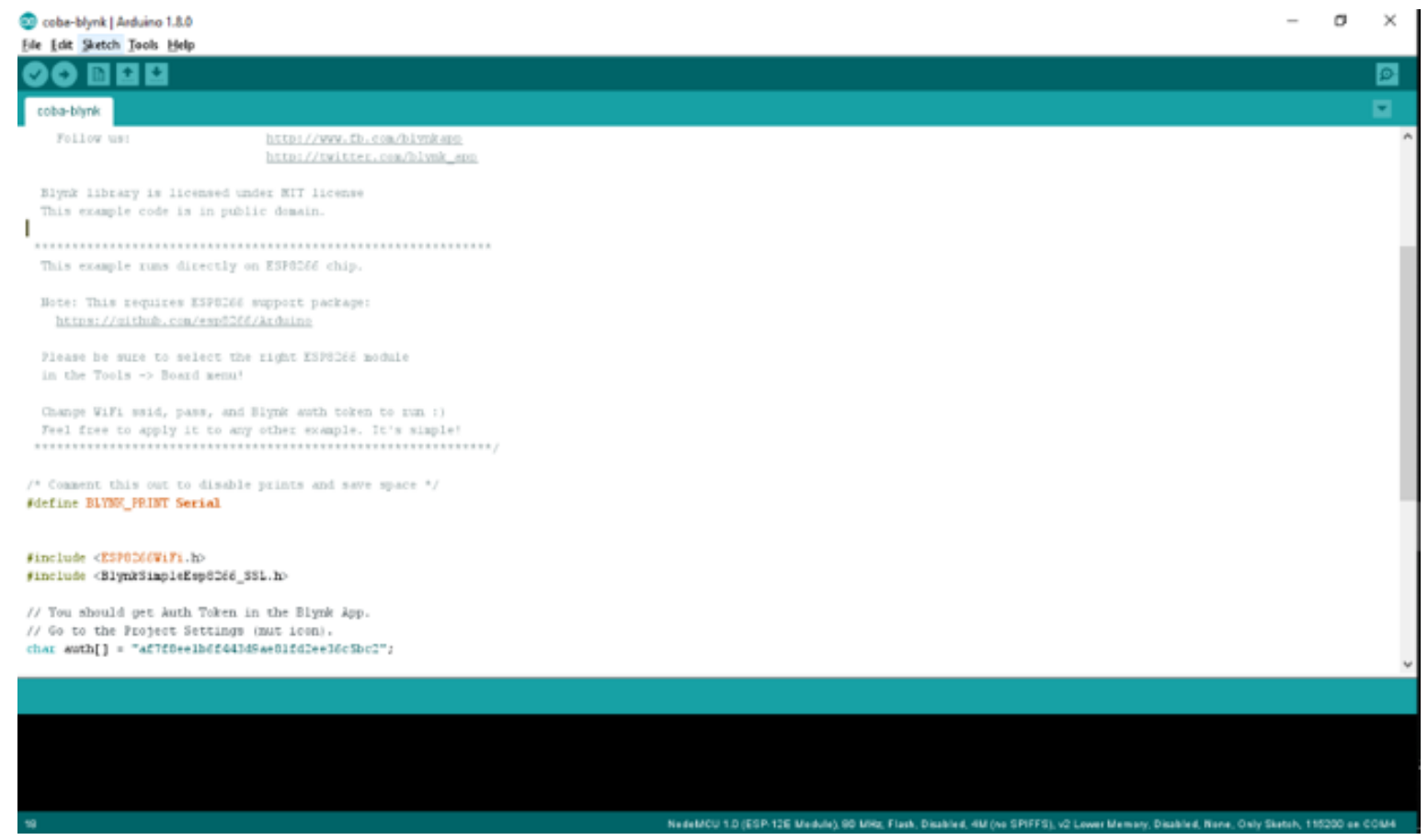

Gambar 6. Pengkodean pada aplikasi Arduino sketch

Peneliti menggunakan server Blynk untuk melakukan pengontrolah terhadap smart power strip dengan menggunakan smartphone

\section{Pengujian sistem.}

Setelah sistem berhasil dibangun, dilakukan pengujian apakah sudah sesuai dengan hasil rancangan. Jika hasil telah sesuai dengan yang diharapkan maka bisa dikatakan penelitian 
yang dilakukan berhasil, akan tetapi jika ada kendala atau masalah yang manyebabkan sistem ini tidak dapat berjalan sebagaimana yang diharapkan maka peneliti harus mengkaji lagi dari tahapam awal yaitu analisa kebutuhan untuk mengetahui secara detail dimana yang terdapat kekurangan ataupun kesalahan. Pada tahapan ini akan dilakukan siklus pengulangan terus jika hasil dari penelitian masih tidak sesuai dengan apa yang diharapkan.

\section{Penulisan Laporan.}

Setelah pengujian berhasil, dilakukan proses penulisan laporan penelitian. Laporan ini merupakan tahapan akhir dari pengerjaan sebuah penelitian yang bertujuan untuk memberikan pertanggungjawaban atas penelitian yang telah dilakukan kepada pihak terkait.

\section{HASIL DAN PEMBAHASAN}

\section{Perangkat Lunak (Software)}

Sistem smart strip ini bertujuan untuk dapat memberikan pekayanan kepada masyarakat dalam hal penghematan pemakaian listrik.Sistem ini dapat melakukan kontrol pemakaian listrik jarak jauh berbasis android, jadi user bisa melakukan pengaktifan dan pengnonaktifan elektronik yang digunakan di rumah dari jarak jauh.

Berikut ini adalah alur kerja aplikasi:

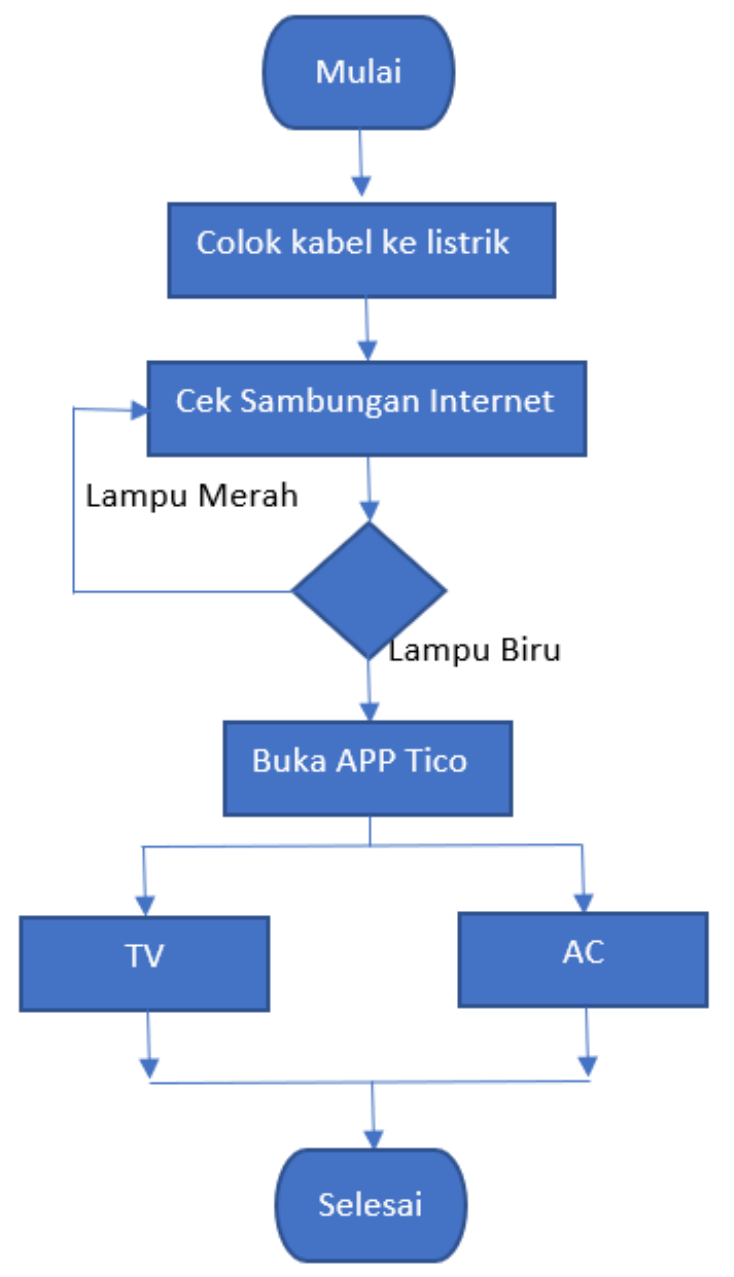

Gambar 7. Alur kerja aplikasi 


\section{KILAT}

Vol. 9, No. 1, April 2020, P-ISSN 2089-1245, E-ISSN 2655-4925

DOI: https://doi.org/10.33322/kilat.v9i1.752

Gambar alur kerja sistem diatas memperlihatkan bagaimana sistem kontrol smart plug yang diakses menggunakan program aplikasi yang di instalkan pada OS android. Yang dilakukan pertama kali adalah user harus memastikan terlebih dahulu terminal sudah tersambung dengan arus listrik melalui kabel listrik, kemudian alat yang sudah tersambung listrik tadi harus disambungkan dengan dengan media internet, yang internet berguna sebagai penghubung antara alat yang akan $\mathrm{d}$ kontrol dengan smartphone android. Kemudian setelah tersambung dengan internet, user harus memastikan lagi hubungan tersebut melalui lampu yg terdapat di relay, jika lampu yang hidup warna merah maka artinya internet belum tersambung, dan sebaliknya, jika yang hidup lampu biru artinya alat yang akan di kontrol tersambung dengan internet. Lalu setelah semuanya yakin terhubung, maka user membuka aplikasi TICO di smartphone android sebagai alat kontrol dari alat terminal tadi dari jarak jauh. Akan terdapat beberapa pilihan untuk kontrol elektronik didalam aplikasi tersebut apakah ingin di hidupkan (ON) atau di matikan (OFF). Untuk lebih jelasnya dapat diperhatikan gambar dibawah ini.

1. Node MCU dan Relay

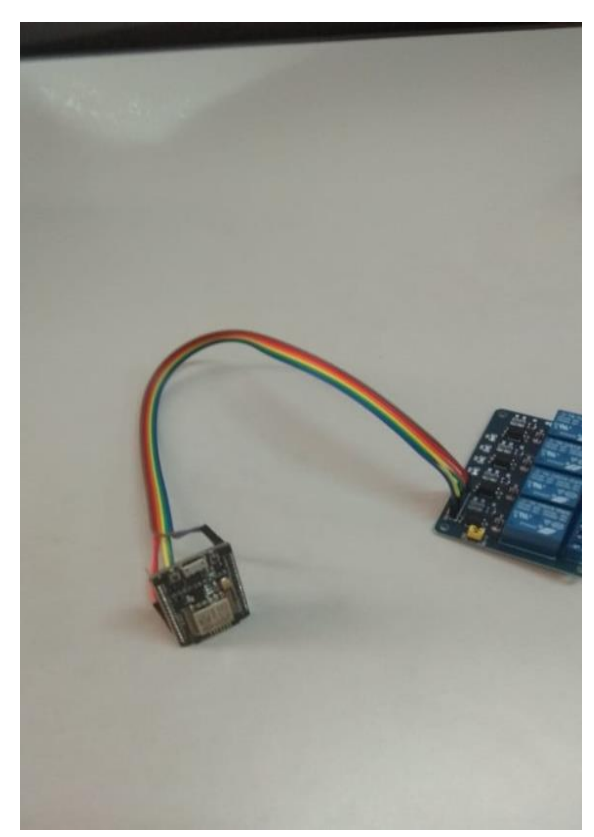

Gambar 8. Node MCU dan Relay

Tampilan gambar diatas memperlihatkan bagian dari bahan dasar terbentuknya smart plug. Bahan tersebut dikenal sebagai node MCU (Kiri layar) dan Relay (kanan layar) yang menjadi perantara antara sinyal yang akan ditangkap oleh terminal sehingga terminal dapat melakukan eksekusi apakah kita ingin menghidpkan atau mematikan elektronik listrik yang kita sambungkan 
2. Perangkat Smart Plug

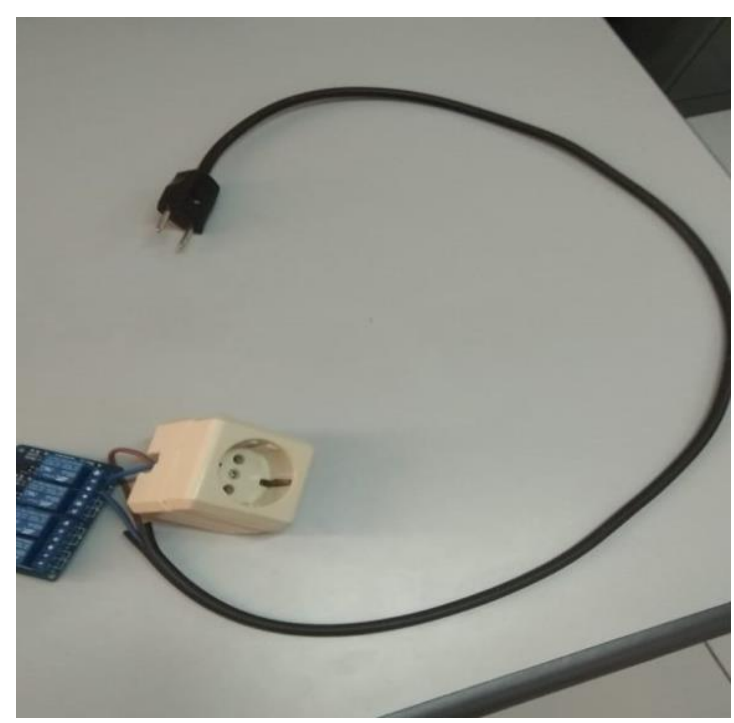

Gambar 9. Perangkat Smart Plug

Tampilan gambar diatas memperlihatkan perangkat Node MCU dan relay telah tersambungkan dengan terminal, yang kemudian diantara sambungan dua perangkat tersebut juga disambung sebuah kabel yang berguna untuk menghantar arus listrik. Artinya kabel tersebut akan menjadi perantara arus utama atau induk dari aliran arus listrik yang akan di terima oleh perangkat elektronik, dan alat diataslah yang disebut dengan Smart Plug.

3. Tampilan awal Aplikasi
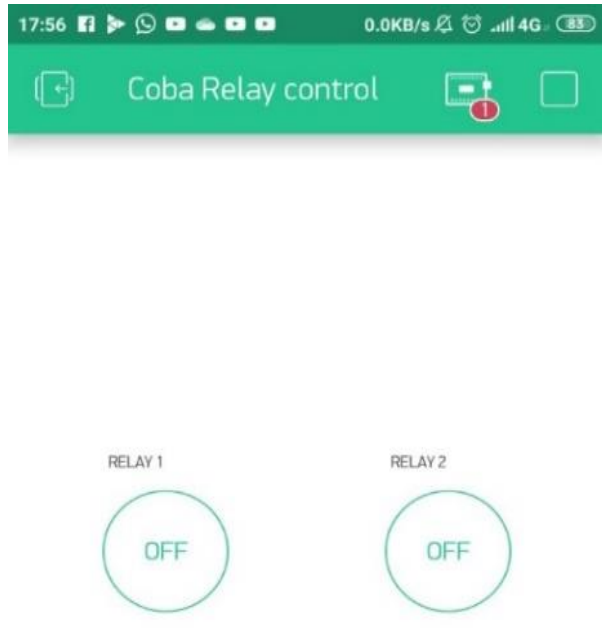

Gambar 10. Tampilan awal 


\section{KILAT}

Vol. 9, No. 1, April 2020, P-ISSN 2089-1245, E-ISSN 2655-4925

DOI: https://doi.org/10.33322/kilat.v9i1.752

Setelah dibangun perangkat keras yang berguna sebagai alat yang akan kita kontrol, maka setelah itu dilakukan pemrograman dengan tools android studio yang tentunya dapat diimplementasikan pada perangkat smartphone android juga. Pada gambar di atas terlihat prototype sederhana hasil dari program yang mana memperlihatkan 2 buah button sederhana dan dapat ditambah jumlah button nya sesuai dengan berapa banyak elektronik yang ingin kita kontrol. Dan setelah dimodifikasi sesuai dengan berapa buah elektronik yang akan kita kontrol, maka tampilan halaman akan berunah seperti dibawah ini.
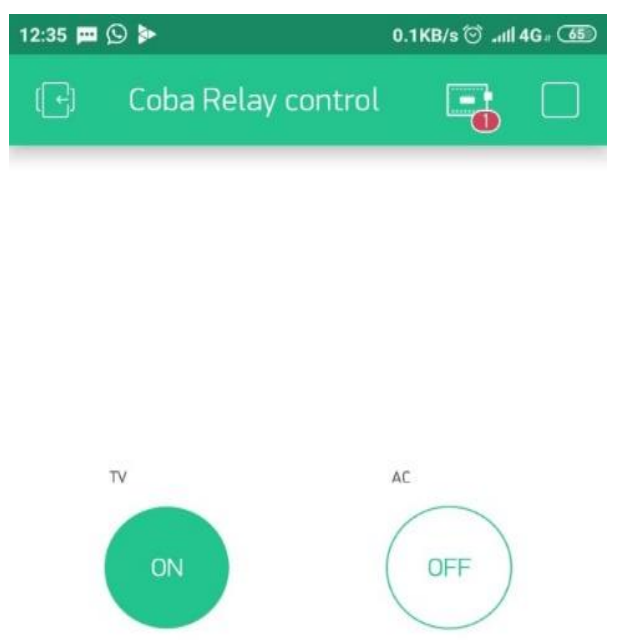

Gambar 11. Tampilan Awal (Modifikasi)

Tampilan di atas terlihat aplikasi yang telah dibangun tadi juga dilengkapi dengan jenis elektronik apa saja yang ingin kita kontrol dari jarak jauh. Dapat dilihat juga bahwa ketika kita ingin menghidupkan televisi maka tinggal menekan tombol yang mempunyai keterangan televisi dan otomatis tulisan button yang tadinya off berubah menjadi on.

\section{KESIMPULAN DAN SARAN}

\section{Kesimpulan}

Kesimpulan umum yang bisa disampaikan sementara adalah sebagai berikut

1. Aplikasi Smart Power Strip ini dapat mengontrol peralatan listrik menggunakan Smartphone.

\section{Saran}

Adapun saran yang bisa disampaikan adalah:

1. Perlu adanya fitur monitoring untuk setiap penggunaan peralatan listrik yang digunakan. 


\section{UCAPAN TERIMAKASIH}

Penulis mengucapkan terima kasih kepada Instansi/perusahaan/lembaga yang telah memberi dukungan yang membantu pelaksanaan penelitian dan atau penulisan artikel.

\section{DAFTAR PUSTAKA}

[1] Chakraborty N, M. A. (2018). Efficient scheduling of nonpreemptive appliances for peak load optimization in smart grid. IEEE Transactions on Industrial Informatics, 3447-3458.Legino, S., \& Arianto, R. (2017). Solving Large Scale Unit Dilemma in Electricity System by Applying Commutative Law. In The International Conference on Mathematics: Pure, Applied and Computation (ICoMPAC). Surabaya, Indonesia: (Presented: November 1, 2017).

[2] KARDIANA, Dhimas Cahya; SAYEKTI, Ilham. PENGONTROL PERANGKAT LISTRIK RUMAH TANGGA MENGGUNAKAN SMARTPHONE BERBASIS ANDROID. Prosiding Sentrinov (Seminar Nasional Terapan Riset Inovatif), [S.1.], v. 1, n. 1, p. 372-396, nov. 2015. ISSN 2477-2097. Available at:

<http://proceeding.sentrinov.org/index.php/sentrinov/article/view/43>. Date accessed: 26 aug. 2019.Pääkkönen, A., Tolvanen, H., \& Rintala, J. (2018). Techno-Economic Analysis Of A Power To Biogas System Operated Based On Fluctuating Electricity Price. Renewable Energy, 117, 166-174. https://doi.org/10.1016/j.renene.2017.10.031

[3] Lakshminarayana V, R. P. (2017). Design and implementation of smart plug with energy monitoring system using IoT. Indian Journal of Public Health Research and Development, 114-117. doi:10.5958/0976-5506.2017.00254.6Wang, A. L., Damartzis, T., Diethelm, S., Herle, J. Van, \& Marechal, F. (2018). Thermo-Economic Evaluation of Sustainable Biogas Upgrading via Solid-Oxide Electrolysis. Energy and Power Engineering, 12(4), 1607.

[4] Santoso B, M. I. (2014). Pemodelan Monitoring Pemakaian Dan Penghematan Energi Listrik Dengan Teknologi Jaringan Sensor Nirkabel. Seminar Nasional Teknologi Informasi dan Komunikasi, 2089-9813.

[5] Wicaksono, M. F. (2017). Implementasi Modul Wifi Nodemcu Esp8266 Untuk Smart Home. Jurnal Teknik Komputer Unikom, 1-6. 